Table 2. 'Over' experiments

\begin{tabular}{|c|c|c|c|c|c|c|c|c|}
\hline \multirow{2}{*}{$\begin{array}{l}\text { Expt. } \\
\text { No. }\end{array}$} & \multirow{2}{*}{ Date } & \multirow{2}{*}{$\begin{array}{c}\text { Rate } \\
\text { of flow } \\
\text { in litres } \\
\text { (at N.T.P.) } \\
\text { per hr. }\end{array}$} & \multicolumn{2}{|c|}{$\begin{array}{c}\text { Observa- } \\
\text { tions }\end{array}$} & \multirow{2}{*}{$\stackrel{\log }{R}$} & \multirow{2}{*}{ Initial } & \multicolumn{2}{|c|}{${ }_{\text {Final }}^{\mathrm{CO}_{2}}$ content } \\
\hline & & & $\begin{array}{l}\text { Period } \\
\text { (sec.) }\end{array}$ & $\begin{array}{l}\text { No. } \\
(N)\end{array}$ & & & $\frac{\text { Mean }}{\text { (of } N \text { ) }}$ & Range \\
\hline \multicolumn{9}{|c|}{ (a) Pelargonium zonale } \\
\hline 23 & | 25. $8.39 \mid$ & $1 \cdot 89$ & 100 & 4 & $\overline{1} \cdot 297$ & 0.0298 & $0 \cdot 0174$ & $0 \cdot 0119-0 \cdot 0238$ \\
\hline \multirow{2}{*}{ ", } & , & ", & ", & 4 & $\overline{1} \cdot 134$ & , & 0.0091 & $0.0076-0.0110$ \\
\hline & $"$, & $1 \cdot 01$ & , & 4 & $\overline{1} \cdot 029$ & ", & $0 \cdot 0054$ & $0.0016-0.0105$ \\
\hline ", & $"$ & $1 \cdot 89$ & $"$ & 4 & $2 \cdot 872$ & $"$ & 0.0074 & $0.0068-0.0085$ \\
\hline \multirow[t]{2}{*}{17} & 17. 7.39 & $1 \cdot 00$ & ", & 4 & $\overline{\underline{1}} \cdot 671$ & $0 \cdot 184$ & 0.0574 & $0.0431-0.0782$ \\
\hline & ", & $"$ & , & 9 & $\overline{\mathbf{I}} \cdot 398$ & - & 0.0229 & $0.0080-0.0319$ \\
\hline 20 & 26. 7.39 & $1 \cdot 02$ & $"$, & 4 & $\underline{\underline{1}} \cdot 994$ &, & $0 \cdot 1021$ & $0 \cdot 0861-0 \cdot 1203$ \\
\hline \multirow[t]{2}{*}{$"$} & ", & $"$ & , & 8 & $\overline{2} \cdot 950$ & 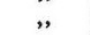 & 0.0223 & $0.0132-0.0282$ \\
\hline & , & , , & , & 4 & $\overline{2} \cdot 929$ & ", & 0.0278 & $0.0266-0.0297$ \\
\hline \multicolumn{9}{|c|}{ (b) Begonia sanguineum } \\
\hline \multirow[t]{2}{*}{14} & 18.11 .38 & 1.92 & 100 & 4 & $\overrightarrow{1} \cdot 989$ & 0.0298 & $0 \cdot 0169$ & $0.0152-0.0199$ \\
\hline & "' & " & ," & 8 & $\overrightarrow{1} \cdot 854$ & , & 0.0132 & $0.0109-0.0163$ \\
\hline 15 & 22.11 .38 & $1 \cdot 88$ & , & 4 & $0 \cdot 121$ & , & 0.0173 & $0.0146-0.0215$ \\
\hline$"$ & ," & ", & , & 9 & $0 \cdot 033$ & " & 0.0163 & $0.0117-0.0233$ \\
\hline \multirow{3}{*}{$\begin{array}{l}11 \\
12\end{array}$} & 10.11 .38 & $1 \cdot 02$ & 120 & 10 & 0.074 & 0.143 & 0.0578 & $0.0409-0.0686$ \\
\hline & 15.11 .38 & $1 \cdot 03$ & 110 & 4 & $0 \cdot 288$ & , & 0.0717 & $0 \cdot 0591-0 \cdot 0951$ \\
\hline & , & , & 100 & 6 & $0 \cdot 122$ & $"$ & 0.0422 & $0.0335-0.0493$ \\
\hline
\end{tabular}

estimating the mean carbon dioxide content to which the leaf is exposed and using such an estimate to correct assimilation data to a constant carbon dioxide content. With relatively elosed stomata (high $\log R$ ) or with higher initial carbon dioxide contents, the Pelargonium leaves failed to reduce the concentration to the 'threshold value'; but even with 0.184 per cent carbon dioxide the depletion was severe and amounted to about 88 per cent of the total content in some cases.

The Begonia results are of some interest, for whereas in 'through' experiments (Table 1) the uptake of carbon dioxide was almost the same as for Pelargonium, in 'over' experiments (Table 2) the latter proved appreciably the more efficient. This might be expected from the small and localized areas of stomata and the long internal diffusion paths to the chlorenchyma in the Begonia leaf?.

surface, and the carbon dioxide of respiration produced in the cytoplasm. Owing to the latter, the carbon dioxide tension at the cell surface could never fall to zero even if carbon dioxide - free air were drawn through the leaf. (Unfortunately this experiment was not carried out owing to the outbreak of war.) That the carbon dioxide content of the air emerging should fluctuate so closely about 0.01 per cent over a wide range of rates of supply indicates that a similar value might be expected with a very slow stream of carbon dioxide - free air passed through the leaf, and this suggestion is supported by Gabrielsen's closed-system experiments. The results, in fact, appear consistent with his hypothesis of a threshold concentration for photosynthesis, though it appears improbable that a true threshold value should exist.

It is clear that in the present experiments, over the range of rates of carbon dioxide supply used, carbon dioxide was very severely 'limiting'. It appears that once inside the leaf all the carbon dioxide except the 0.01 per cent (approx.) is taken up with great efficiency. Some results from experiments in which air was passed over the leaf surface instead of through the intercellular spaces are presented in Table 2 for comparison with those in Table 1. Here the carbon dioxide had to diffuse into the leaf through the stomata. In the case of Pelargonium, when the stomata were relatively widely open (low ' $\log R$ ') and the normal 0.03 per cent initial carbon dioxide concentration was used, the air leaving the leaf chambers showed the same low concentration as in the 'through' experiments, although the leaf area concerned was now only 9 sq. $\mathrm{cm}$. This result was doubtless due to the design of the leaf chambers ${ }^{6}$, which reduced the diffusion path to the leaf surface to at most $2 \mathrm{~mm}$.; it is of importance as indicating that in similar 'over' assimilation experiments, carried out with non. turbulent flow of normal air but in the more usual and deeper types of leaf chamber, the carbon dioxide content near a part of the leaf surface may, in fact, be down to the 'threshold concentration', although the emerging air may show a much higher average value. This would render doubtful the effective area of leaf; it also stresses the need for caution in
The value of approximately 0.01 per cent indicated for the carbon dioxide content of the air in the intercellular space system of a brightly illuminated leaf is of especial interest in view of a recent extension of the discovery of the sensitivity of the stomata to small changes of carbon dioxide tension'. In the further investigation of the response of wheat stomata to carbon dioxide, experiments carried out by Dr. F. L. Milthorpe in this Institute have shown that although there is very marked stomatal opening with reduction of carbon dioxide in the air supply from 0.03 per cent to 0.01 per cent, from 0.01 per cent to zero there is no evidence of any further opening. It appears likely, therefore, that the stomata respond only down to the minimum carbon dioxide content that normally occurs in the sub-stomatal cavities. Any response below this level would, of course, be of no biological advantage to the plant.

Detailed publication of the investigations mentioned will follow in due course, and further work along these lines is projected.

${ }^{1}$ Gabrielsen, E. K., Nature, 161, 138 (1948).

${ }^{2}$ Gabrielsen, E. K., Nature, 183, 359 (1949).

sudus, L. J., Ann. Bot., 11, 165 (1947).

4 Blackman, F. F., Phil. Trans. Roy. Soc., B 186, 503 (1895),

' Maskell, E. J., Proc. Roy. Soc., B, 102, 467 (1928).

- Heath, O. V. S., Ann. Bot., 3, 469 (1939).

"Gregory, F. G., and Pearse, H. L., Proc. Roy. Soc., B, 114, 477 (1984). ${ }^{8}$ Heath, O. V. S., Ann. Bot., 5, 455 (1941).

Heath, O. V. S., Nature. 161, 178 (1948).<smiles>CCC1(C)CCCC1C(C)(C)C</smiles>

\section{AMINO-ACIDS AND PROTEIN HYDROLYSATES}

THERE As ${ }^{2}$ large and attentive audience, including participants from the Continent of Europe, at each session of the recent symposium upon "Arhitho-Acids and Protein Hydrolysates" organised by the Food Group of the Society of cremical Industry. The symposium consisted of six pap $x$-reading sessions held in the William Beveridge Hall at the Senate House, University of London, and an exhibition of relevant equipment and techniques presented in the Physical Chemical Laboratory, 
Imperial College of Science and Technology, South Kensington. The symposium opened on the evening of September 28 with an introductory address by Prof. E. C. Dodds. Prof. H. D. Kay was in the chair. Prof. Dodds had been asked to introduce the subject of the symposium by providing, within the space of a little more than one hour, a reasonably elementary review of the chemistry and biochemistry of the amino-acids, and he fulfilled this task admirably. He reviewed the history, discovery, chemistry and the properties of amino-acids, and followed on to a discussion on methods of synthesis. He rounded off this section of his address by discussing the modern thiazolone method of synthesis in which, starting with hydrocyanic acid, formaldehyde and ammonium chloride, a series of operations easily conducted at room temperature leads to high yields.

Prof. Dodds then turned to the metabolism of amino-acids and, after discussing the metabolic phenomena of deamination, transamination and specific dynamic action, reviewed modern work on this subject, such as the use of paper chromatography in the examination of venous blood following the ingestion of protein, the study of urinary patterns, and the use of 'tagged' atoms and 'double-tracers' to follow the metabolic paths of individual amino-acids. Then came a section on the clinical uses of protein hydrolysates for famine conditions and premature babies, and the therapeutic use of amino-acids, such as methionine and glutamic acid. Finally, Prof. Dodds considered the use of aromatic amino-acids to study the metabolism of bacteria with the view of discovering new chemotherapeutic agents, and the use of conjugated amino-acids in cancer therapy.

The morning session on September 29, under the chairmanship of Dr. Norman C. Wright (chief scientific adviser to the Ministry of Food), was opened by Dr. $\mathrm{K}$. Bailey, who discussed the value of histograms in the interpretation of the analytical data of proteins. Dr. Bailey pointed out that hitherto such analytical data have been capable of only limited interpretation and that there is now a definite need for the situation to be remedied, since the development of new methods of analysis has made it possible for almost all the nitrogen of many proteins to be accounted for in terms of individual amino-acids. He then exhibited histograms relating to the frequency of occurrence of individual amino-acids in a number of different proteins over fairly small units of grouping, for example, 5-10 amino-acid residues $/ 10^{5} \mathrm{gm}$. of protein, and also histograms illustrating the frequency of occurrence of groups of amino-acids such as those with polar side-chains. Dr. Bailey discussed the conclusions to be drawn from the narrowness of the frequencyrange within which various amino-acids fall, from a consideration of groups of amino-acids and also from the histograms of different groups of proteins. Finally, he emphasized the limitations imposed upon this method of approach by the small number of proteins which have been completely analysed, and the difficulty of establishing the criteria by which the proteins are selected.

This paper was followed by one by Dr. A. Neuberger upon the modern development of structural protein chemistry. Dr. Neuberger pointed out that during the period up to 1914, the structures of most aminoacids were determined, the presence of polypeptide chains in proteins was demonstrated and methods for the synthesis of peptides developed; the period between the two World Wars saw the introduction of physical methods into the field of protein chemistry.
The molecular size and shape of many proteins were determined and the effect of electrostatic factors appreciated. Electrophoresis and potentiometric titrations gave a lot of new information about charged groups in proteins, and the multipolar character of proteins even in the isoelectric state was recognized. Dr. Neuberger then discussed some of the problems facing protein chemists at the present time. $\mathrm{He}$ explained that the resonance of the amide group is probably connected with the ability of peptide bonds to form hydrogen bonds, and that this resonance is likely to vary to some extent with the molecular environment of the bond in question and with the character of the side-chains. Attention was directed to modern work showing that bonds or forces other than amide bonds must be responsible for holding polypeptide chains together to produce the specific configuration of the native protein molecule. Weak covalent bonds of unknown type may be involved, but their presence or absence is difficult to prove. Hydrogen bonds and other electrostatic forces are likely to be responsible for the reversible association of some proteins, but the simple picture of salt linkages is not acceptable. Finally, Dr. Neuberger emphasized the importance of steric factors.

This session of the symposium ended with a paper by Dr. G. R. Tristram in which he reviewed methods of analysis other than chromatographic and micro. biological techniques. $\mathrm{He}$ discussed ionophoresis, periodate oxidation, isotope dilution using stable and radioactive elements, and enzymatic methods which rely upon the use of specific enzymes. He then discussed with illustrative data the criteria suggested for the establishment of the accuracy and specificity of any method and the limitations imposed upon the interpretation of amino-acid data by the accuracy of the analysis.

The afternoon of September 29 was given over to an exhibition, held in the Physical Chemical Labora. tory at the Imperial College of Science and Technology. The exhibits covered equipments and techniques employed in amino-acid analysis and the determination of nitrogen balance, electron micrographs, commercial syntheses of amino-acids, the commercial manufacture of protein hydrolysates, the amino-acid-sugar reaction responsible for the deterioration of food products and the Craig-Post apparatus for counter-current extraction on a preparative scale.

The first two papers of the evening session of September 29 dealt with amino-acid analysis. The first paper, by Dr. E. C. Barton-Wright, reviewed the microbiological methods of assay, while the second paper, by Dr. R. L. M. Synge, discussed chromatographic methods. Dr. Barton-Wright described the basic technique of the microbiological method of amino-acid assay and then discussed in some detail the composition of the basal media and the stimulatory effect of some amino-acids. The statistical treatment of response curves by the $\log / \log$ relationship was described, and advantages of the microbiological techniques over chemical methods were reviewed.

Dr. Synge described different chromatographic procedures involving ion exchange and molecular adsorption or partition between liquid phases, and discussed various analytical problems in which. chromatographic methods have been especially useful. $\mathrm{He}$ also explained how the techniques selected should be governed by the purpose of the analysis since, for example, the rapid analysis of foodstuffs and the 
removal of interfering amino-acids by stripping require different approaches.

Dr. C. H. Lea gave the final paper of this session, and of the first day of the symposium; he considered the role of amino-acids in the deterioration of food. He explained how a reaction between amino-acids and reducing sugars is responsible for deteriorative changes in flavour, colour, solubility and other properties in a wide variety of foodstuffs, and he reviewed the effect of humidity and temperature on these changes. He reported that reaction occurs with various amino-acid side-chains, including arginine, histidine, tyrosine and methionine, but that the combination would seem to involve something more than $\mathrm{N}$-glycoside formation.

The morning session of September 30 was devoted to only two papers. The opening paper, by Dr. C. Ockrent and colleagues, dealt with the manufacture of amino-acids. Having reviewed the many uses of amino-acids, Dr. Ockrent explained that the optically active $\mathbf{L}$-isomers are obtained commercially by separating them from the acid or enzymic hydrolysate of proteins, while the racemic DL-forms are manufactured synthetically. Examples were given of the separation of individual optically active amino-acids involving the use respectively of flavianic acid, picric acid and copper carbonate, and then Dr. Ockrent concentrated upon methods of synthesis. $\mathrm{He}$ discussed, with the aid of slides showing each step of the reactions, a series of commercially applicable methods of synthesis and a few methods mainly of academic interest.

This paper was followed by one by Dr. S. M. Partridge upon the use of displacement chromato. graphy as a preparative method for amino-acids. Dr. Partridge described the use of columns of synthetic resinous ion exchangers for the separation of amino-acid mixtures, and explained how fractionation can be accomplished by displacement from a cationexchenge resin with a strong base. He described with the aid of slides an apparatus for the automatic collection of fractions from a displacement experiment, and showed how the purity of each collected fraction can be determined by paper chromatography.

The first of the two papers presented in the afternoon of September 30, which was by Dr. G. M. Dyson and Mr. E. M. Bavin, was concerned with the manufacture of protein hydrolysates. Dr. Dyson first discussed the consideration which decides the choice of protein material, and then explained that the main problems associated with large-scale manufacture are the elimination of pyrogens, the elimina. tion of pressor and depressor substances, adequate hydrolysis of the protein and prevention of tyrosine deposition. He explained the various factors which influence these problems, and the steps taken to ensure that they are adequately dealt with. Dr. Dyson then gave a detailed description of the plant and process employed in large-scale production of protein hydrolysates, and discussed the rigorous control tests to which they are subjected.

Dr. Dyson's paper was followed by one from Dr. H. G. Rees upon the application of amino-acids and protein hydrolysates in the food industry. In this paper the methods available for the preparation of hydrolysed products for the flavouring of foods were considered. Dr. Rees then dealt more specifically with the use of monosodium glutamate as a food adjunct and discussed the history of this product and modern methods of manufacture.
The final session of the symposium was devoted to an address by Dr. D. P. Cuthbertson on amino-acids and protein hydrolysates in human and animal nutrition. Dr. Cuthbertson discussed in some detail the metabolism of proteins and amino-acids and then gave consideration to protein requirements in health and convalescence, protein insufficiency and the effects of trauma and infection. $\mathrm{He}$ stressed that dietary surveys conducted in temperate regions indicate that, at all ages from one year onwards and at all energy-levels, the protein intake expressed as a percentage of total calories is reasonably constant at 11-14 per cent. In a following section of his paper, Dr. Cuthbertson discussed the use of protein hydrolysates by intravenous injection and by tube into the alimentary canal, and summed up by saying that there is no solid evidence that there is any special value to be derived from such procedures. Dr. Cuthbertson also mentioned the subject of infusing sufficient protein (and energy) by intravenous injection, and suggested that the necessary indications for parenteral feeding are inability to ingest, digest or absorb adequate quantities of food over such a period of time as would jeopardize convalescence or even the chance of survival.

\section{EFFECT OF LOW FAT INTAKES AND OF CRUDE FIBRE ON THE ABSORPTION OF FAT

$$
\text { BY DR. A. R. P. WALKER }
$$

Nutrition Unit, Council/or Scientfiic and Industrial Research, South Africap' Institute for Medical Research, Johannesburg

T is well known that fat is well absorbed by man when consurmed in amounts of 50-150 gm. per day. Under these conditions, the apparent absorption of fat $\left(\frac{I-F}{I} \times 100\right.$, where $I$ is intake of fat and $F$ the rmount excreted in the fæces) is more than 90 per cent, less than this proportion being considered pathological. When the intake of fat is relatively low, however, the apparent percentage absorption is greatly reduced $(58-62 \text { per cent })^{1,2}$. The purpose of this communication is to provide evidence that the fat which is excreted in the fæces, and which is assumed to be unabsorbed fat in calculating the apparent absorption, is mainly of non-dietary origin, and that the true absorption of fat is not necessarily lower when the intake of fat is reduced. The evidence, which is based on the study of diets of different fat and crude fibre contents, also indicates that the additional amount of fat which is excreted in the fæces when the fibre content of a diet is greatly increased $^{3}$ is not unabsorbed fat, but is probably wholly of endogenous origin.

Balance observations were carried out on a healthy European male subject of thirty-five years of age, over a period of 124 consecutive days. During this period the intake of fat was maintained at four different levels, ranging from 61 down to $3 \mathrm{gm}$. per day; the fibre intake was controlled to yield stools of different weight, the normal stool averaging 30 $35 \mathrm{gm}$. dry fæces per day, the moderately large 40$45 \mathrm{gm}$., and the very large 60-70 gm. Each successive level of fat and fibre intake was given until the average amount of fæcal fat excreted daily remained 